\title{
Losing Neutrality: The Neural Basis of Impaired Emotional Control without Sleep
}

\author{
[Dti Ben Simon, ${ }^{1,2}$ Noga Oren, ${ }^{1,2}$-Haggai Sharon, ${ }^{1,2}$ Adi Kirschner, ${ }^{3}$ Noam Goldway, ${ }^{3}$ Hadas Okon-Singer, ${ }^{5}$ \\ Rivi Tauman, ${ }^{2,6}$ Menton M. Deweese, ${ }^{7}$ Andreas Keil, ${ }^{7}$ and Talma Hendler ${ }^{1,2,3,4}$ \\ ${ }^{1}$ Functional Brain Center, Wohl Institute for Advanced Imaging, Tel Aviv Medical Center, Tel Aviv 6423906, Israel, ${ }^{2}$ Sackler Faculty of Medicine and ${ }^{3}$ Sagol \\ School of Neuroscience and ${ }^{4}$ School of Psychological Sciences, Tel Aviv University, Tel Aviv 6997801, Israel, 5 Department of Psychology, University of \\ Haifa, Haifa 3498838, Israel, ${ }^{6}$ Sleep Disorders Center, Tel Aviv Medical Center, Tel Aviv 6330303, Israel, and ${ }^{7}$ Center for the Study of Emotion and Attention, \\ University of Florida, Gainesville, Florida 32611
}

Sleep deprivation has been shown recently to alter emotional processing possibly associated with reduced frontal regulation. Such impairments can ultimately fail adaptive attempts to regulate emotional processing (also known as cognitive control of emotion), although this hypothesis has not been examined directly. Therefore, we explored the influence of sleep deprivation on the human brain using two different cognitive- emotional tasks, recorded using fMRI and EEG. Both tasks involved irrelevant emotional and neutral distractors presented during a competing cognitive challenge, thus creating a continuous demand for regulating emotional processing. Results reveal that, although participants showed enhanced limbic and electrophysiological reactions to emotional distractors regardless of their sleep state, they were specifically unable to ignore neutral distracting information after sleep deprivation. As a consequence, sleep deprivation resulted in similar processing of neutral and negative distractors, thus disabling accurate emotional discrimination. As expected, these findings were further associated with a decrease in prefrontal connectivity patterns in both EEG and fMRI signals, reflecting a profound decline in cognitive control of emotion. Notably, such a decline was associated with lower REM sleep amounts, supporting a role for REM sleep in overnight emotional processing. Altogether, our findings suggest that losing sleep alters emotional reactivity by lowering the threshold for emotional activation, leading to a maladaptive loss of emotional neutrality.

Key words: amygdala; cognitive-emotional interactions; emotion; fMRI; sleep deprivation; ssVEP

\section{Significance Statement}

Sleep loss is known as a robust modulator of emotional reactivity, leading to increased anxiety and stress elicited by seemingly minor triggers. In this work, we aimed to portray the neural basis of these emotional impairments and their possible association with frontal regulation of emotional processing, also known as cognitive control of emotion. Using specifically suited EEG and fMRI tasks, we were able to show that sleep deprivation alters emotional reactivity by triggering enhanced processing of stimuli regarded previously as neutral. These changes were further accompanied by diminished frontal connectivity, reduced REM sleep, and poorer performance. Therefore, we suggest that sleep loss alters emotional reactivity by lowering the threshold for emotional activation, leading to a maladaptive loss of emotional neutrality.

\section{Introduction}

Sleep plays a key role in protecting our emotional well-being. A single night of sleep deprivation (SD) is known to trigger emo-

\footnotetext{
Received April 6, 2015; revised July 12, 2015; accepted Aug. 19, 2015.

Author contributions: E.B.S., N.O., H.S., and T.H. designed research; E.B.S., A.Ki., and N.G. performed research; R.T., M.M.D., and A.Ke. contributed unpublished reagents/analytic tools; E.B.S., N.O., A.Ki., N.G., M.M.D., and A.Ke. analyzed data; E.B.S., H.S., H.O.-S., and T.H. wrote the paper.

This study was supported by the Ministry of Science, Technology, and Space Israel, the US Department of Defense (grant agreement number W81XWH-11-2-0008), the Sagol Foundation for Human Neuroscience, and Israel Centers of Research Excellence Program of the Planning and Budgeting Committee and Israel Science Foundation Grant 51/11. The work of Hadas Okon-Singer was supported by the Marie Curie Actions CIG Grant 34206 and the National Institute for Psychobiology in Israel Young Investigator Research Grant 145-14-15.

The authors declare no competing financial interests.
}

tional difficulties (Pilcher and Huffcutt, 1996; Anderson and Platten, 2011), leading to increased subjective stress and anxiety (Minkel et al., 2012) and enhanced sympathetic reactions to unpleasant stimuli (Zhong et al., 2005; Franzen et al., 2009). Chronically disturbed sleep further amplified the negative effect of disruptive events (Zohar et al., 2005) and impaired cognitive reappraisal of negative stimuli (Mauss et al., 2013), demonstrating

Correspondence should be addressed to either Eti Ben Simon or Talma Hendler, Functional Brain Center, Woh Institute for Advanced Imaging, Tel Aviv Medical Center, 6 Weizmann Street, Tel Aviv 6423906, Israel. E-mail: etoosh@gmail.com or talma@tasmc.health.gov.l.

DOI:10.1523/JNEUROSCI.1314-15.2015

Copyright $\odot 2015$ the authors $\quad 0270-6474 / 15 / 3513194-12 \$ 15.00 / 0$ 


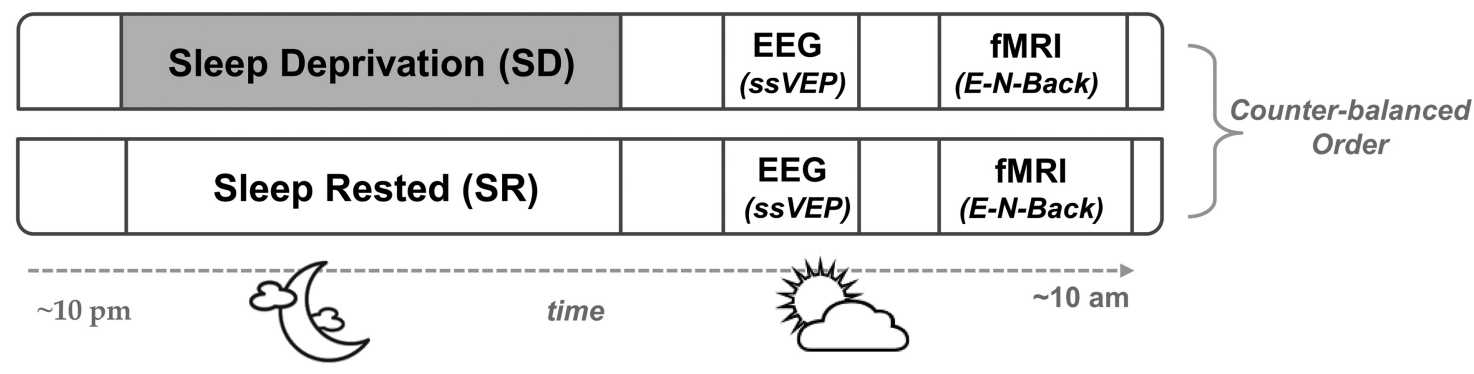

Figure 1. Experimental design. Participants took part in two experimental sessions, involving either monitored sleep-rested or sleep-deprived conditions in a counterbalanced order. In each session, participants performed two tasks including a cognitive challenge simultaneously presented with neutral or emotional distractors: first using ssVEPs during EEG recording and then using an emotional $N$-back (E-N-Back) task during fMRI acquisition.

an accumulating effect of sleep loss on emotional well-being. Accordingly, interrupted sleep is a prominent symptom in nearly all affective disorders, recently suggested to play a causal role in the etiology of these conditions (Goldstein and Walker, 2014). In contrast, adequate sleep has been consistently associated with improved emotional well-being, specifically related to REM sleep amount and physiology (Gujar et al., 2011a; van der Helm et al., 2011).

At the neural level, emerging neuroimaging findings reveal that $\mathrm{SD}$ is associated with enhanced emotional reactivity signified by increased limbic activation in response to emotional stimuli, specifically within the amygdala. These activations were further coupled with a decrease in the functional connection between the amygdala and the medial prefrontal cortex (PFC) (Yoo et al., 2007; Chuah et al., 2010; Gujar et al., 2011b), typically associated with emotional control (Kim et al., 2011). Interestingly, increased amygdala activation was reported in response to viewing both negative (Yoo et al., 2007) and positive (Gujar et al., 2011b) images, suggesting that sleep loss induces a general increase in emotional reactivity without a specific valence bias. Furthermore, such indiscriminative emotional reactivity could stem from enhanced processing of emotional stimuli or, alternatively, increased processing of stimuli regarded previously as neutral, implicating a profound change in the threshold for emotional activation after SD.

A possible mechanism supporting such a change could be related to impaired top-down modulation of emotional processing, also known as cognitive control of emotion (Ochsner and Gross, 2005). Cognitive control of emotion is crucial for adaptive functioning (Eftekhari et al., 2009), enabling regulation of emotional processing via interactions between prefrontal/cingulate control systems and emotion generative systems. Such regulatory mechanisms have been demonstrated to limit the processing of emotional stimuli (presented either alone or as a distractor during task performance), resulting in reduced amygdala activation and reduced subjective emotional ratings (Ochsner et al., 2012).

Despite emerging links between sleep loss and emotional reactivity, it remains unclear how sleep modulates cognitive control of emotion and its resulting emotional profile. Given previous indications of prefrontal and limbic vulnerability to sleep loss, we aimed to directly examine the effect of sleep on cognitive control of emotion, using two complimentary cognitive-emotional tasks (recorded using fMRI and EEG), while manipulating sleep in a within-subject design. To specifically target the effect of sleep on cognitive-emotional interactions, we applied tasks that include the presentation of distracting emotional stimuli during the performance of a challenging cognitive task (Ochsner and Gross, 2005), thus creating a continuous demand for regulation of emotional processing. Moreover, it has been shown that task-relevant manipulations of either perceptual or cognitive load strongly modulate the response to emotional distractors (Van Dillen et al., 2009), further enabling to examine context-dependent modulation of emotional processing as a function of sleep.

Therefore, our tasks examined the interaction between cognitive/perceptual load and processing of distracting emotional stimuli as a function of sleep, using fMRI/steady-state visually evoked potentials (ssVEPs; Keil et al., 2003; Müller et al., 2008; Deweese et al., 2014), respectively. We hypothesized that SD would impair cognitive control of emotion, manifested as greater activation in limbic and task-related regions in response to emotional distractors, accompanied by diminished frontal connectivity. Last, we hypothesized that lower amounts of REM during the sleep-rested night will correspond to a greater decrease in frontal modulation of both limbic and task-related regions.

\section{Materials and Methods}

Participants. Eighteen adults (age range, 23-32 years; mean, $26.8 \pm 3$ years; 10 females) completed a repeated-measures crossover design. Participants were healthy with no history of sleep, neurologic, or psychiatric disorders (assessed using a detailed medical history questionnaire). Normal sleep-wake patterns were further validated using actigraphy and subjective sleep logs, as detailed below. Recent use of psychostimulants (e.g., Ritalin), psychiatric or hypnotic drugs, and high caffeine consumption $(>3$ cups/d) also excluded subjects from participation in the study. The study was approved by the Tel-Aviv Sourasky Medical Center ethical review board, and all participants provided written informed consent.

Experimental design. Figure 1 describes the sequence of events within the study design. After screening, participants took part in two experimental sessions: (1) once after a night of normal sleep (i.e., the sleeprested condition); and (2) again after $24 \mathrm{~h}$ of supervised SD.

Participants had to abstain from alcohol and caffeine $2 \mathrm{~d}$ before each session and throughout the SD night. To ensure normal sleep-wake patterns (7-9 h of sleep/night) participants were monitored for 3 consecutive days before study participation, using an actigraph (a wristwatch movement sensor sensitive to wake-sleep states; Fitbit) and via subjective sleep logs. These measurements validated that participants were asleep for 7:35 \pm 1:12 h each night, rising at $\sim 8: 06 \pm$ 1:06 A.M. Normal sleep parameters were further validated using an ambulatory sleep device (WatchPAT-100; Itamar Medical) worn the night before the sleep-rested session. The PAT-100 is based predominantly on recordings of peripheral arterial tone (PAT), along with pulse rate, actigraphy, and pulse oximetry (Bar et al., 2003; Pillar et al., 2003; Penzel et al., 2004), shown to accurately detect sleep versus wakefulness (Hedner et al., 2004) differentiate light and deep sleep, and detect REM sleep (Herscovici et al., 2007; Bresler et al., 2008; Hedner et al., 2011). These recordings validated normative sleep parameters for this age range (Table 1) and altogether support the likelihood that participants were well rested before study participation. 
Table 1. Sleep parameters

\begin{tabular}{lcl}
\hline Sleep parameters (mean \pm SD) & Time $(\mathrm{min})$ & Percentage of total sleep time \\
\hline Light sleep & $187.33 \pm 48.36$ & $52.37 \pm 9.52$ \\
Deep sleep & $78.41 \pm 18.39$ & $22.21 \pm 4.62$ \\
REM & $90.59 \pm 28.3$ & $25.42 \pm 6.52$ \\
Time in bed & $410 \pm 65.4$ & \\
Sleep latency & $18.78 \pm 11.32$ & \\
Total sleep time & $356.3 \pm 61.77$ & \\
\hline
\end{tabular}

For the SD session, participants reported to the laboratory at 10:30 P.M., typically at the end of a working day, and were monitored continuously by the research staff. Participants were specifically instructed not to engage in daytime naps during $3 \mathrm{~d}$ prior to the SD session and were debriefed regarding their daily activities on arrival to the laboratory, in order to confirm adherence to the study protocol. Ten subjects were further equipped with an actigraph for the entire day before arrival at the SD session, confirming that the SD day included typical activities of the subjects' routine (e.g., going to the university), not statistically different from their daily activities (mean number of steps before the SD day, 10,271 ; on the SD day, 11,735; $p>0.18$ ). Starting from 11:00 P.M. and every $2 \mathrm{~h}$, participants performed a battery of questionnaires assessing sleepiness and mood (detailed below). The SD session typically included two subjects in the same night, and activity protocol was kept in accordance with previous work (Gujar et al., 2011b; Goldstein et al., 2013). Mainly, participants were allowed access to the Internet, board games, and low-emotionality films; physical activity was restricted to short walks and food intake to a small sandwich at $\sim$ 3:00 A.M. At $\sim$ 8:00 A.M. $( \pm 30$ $\mathrm{min}$ ) of the following morning of each session, participants performed the EEG task and, at $\sim 8: 30$ A.M. ( $\pm 90 \mathrm{~min}$ ), entered the MRI scanner. Test sessions were separated by a mean of $13.8 \mathrm{~d}$ with the order of the sleep-rested and sleep-deprived sessions counterbalanced across participants.

Sleepiness and mood assessments. To assess changes in subjective alertness across the SD night, participants completed the Hebrew version of the Stanford Sleepiness Scale (SSS; Hoddes et al., 1973). This questionnaire consists of seven statements ranging from "feeling active and vital; wide awake" to "sleep onset soon; lost struggle to remain awake." To assess changes in objective sleepiness as well, we further applied a $10 \mathrm{~min}$ version of the known Psychomotor Vigilance Task (PVT; Drummond et al., 2005) using the Psychology Experiment Building Language task library (Mueller and Piper, 2014). Both sleepiness measurements were obtained every $2 \mathrm{~h}$ during the SD night (from 11:00 P.M. to 7:00 A.M.) and in the morning of the sleep-rested session ( 8:00 A.M.).

To track mood changes after sleep loss, the Positive and Negative Affective Scale (PANAS; Watson et al., 1988) was administered every $4 \mathrm{~h}$ across the SD night and on arrival at the sleep-rested session. The PANAS consists of two 10-item questionnaires assessing either positive or negative effect. Participants were asked to rate each item on a scale ranging from 1 to 5 . In addition, participant also used a $10 \mathrm{~cm}$ visual analog scale (VAS) to rate their mood, ranging from terrible to excellent.

fMRI emotional N-back task. To examine the effects of cognitive load on emotional processing as a function of sleep, we developed an emotional version of the well-known $N$-back task (Owen et al., 2005). In this emotional $N$-back task, subjects were asked to monitor a series of numbers and indicate by a button press when the currently presented number is the same as the one presented $N$ trials ago (Fig. $2 a$ ). To alter the emotional load as well, the numbers-to-be-remembered were superimposed on distracting negative or neutral images. Positive pictures were not added to the $N$-back design because of time limitation within the scanner, leading us to favor the negative distractor, more frequently used in cognitive-emotional interactions (Yamasaki et al., 2002; Van Dillen et al., 2009; Chuah et al., 2010; for review, see Iordan et al., 2013). The images used as distractors were taken from the International Affective Picture System (IAPS) standardized pool (Lang et al., 1999); all negative pictures had lower valence level $\left(t_{(142)}=-4.02, p<0.001\right)$ and higher arousal level $\left(t_{(142)}=8.97, p<0.001\right)$ compared with the neutral ones. For the current experiment, 72 negative and 72 neutral pictures were selected. Altogether, the task manipulated two independent factors in a block-design format: cognitive load (low vs high, indicated by the $\mathrm{N}$-backward number to be remembered: 1-back or 2-back, respectively) and emotional load (negative or neutral distractors). A block was composed of nine sequential trials, each presenting a number superimposed on a colored negative or neutral picture (depending on the block), followed by an asterisk. There were three targets in each block; participants were instructed to respond by a button press as soon as they recognized the correct number while reaction time and accuracy scores were measured for each response. Each subject completed two versions of the emotional $\mathrm{N}$-back task counterbalanced across sessions. To help participants remember the block type, numbers were colored differently for each condition (red in the 1-back condition and green in the 2-back, counterbalanced across sessions and participants).

To validate wakefulness during task performance, we tracked subjects' eyes via a dedicated camera during the entire scan. Before the scan, all participants performed a practice block to become familiar with task instructions, which included different distractors than the main experiment. In addition, the first block of the task was always similar to the practice block, to allow subjects to become familiar with performing the task inside the scanner, and was not included in the final analysis. The task lasted 10:09 min and included a total of 17 blocks (four blocks for each experimental condition and a first null block), each lasting $24 \mathrm{~s}$ separated by a pseudorandom fixation period of 9 or $12 \mathrm{~s}$.

$f M R I$ data acquisition and preprocessing. Imaging was performed on a 3T GE Horizon echo speed scanner with a resonant gradient echoplanar imaging system (GE Healthcare). All images were acquired using a standard head coil. The scanning session included functional $\mathrm{T} 2{ }^{*}$-weighted images (FOV, $200 \mathrm{~mm}$; matrix size, $96 \times 96$; voxel size, $3 \times 3 \times 4$; TR, $3000 \mathrm{~ms}$; TE, $35 \mathrm{~ms}$; slice thickness, $4 \mathrm{~mm}$; 32-39 slices without gap, oriented according to the fourth ventricle; flip angle, $90^{\circ}$ ) and a threedimensional anatomical scan using $\mathrm{T} 1$ spoiled gradient-recalled acquisition in a steady state sequence $(1 \times 1 \times 1 \mathrm{~mm})$. SPM8 software (http:// www.fil.ion.ucl.ac.uk/spm) was used for image preprocessing and voxelbased statistical analysis. The first $18 \mathrm{~s}$ of the functional data were discarded to allow steady-state magnetization. Functional images were motion corrected and slice-time corrected, realigned to the first scan, and normalized according to standard MNI space. Spatial smoothing was performed using a Gaussian kernel (FWHM of $6 \mathrm{~mm}$ ).

$f M R I$ analysis. For each subject, a general linear model was specified, including a vector of condition onsets convolved with a canonical hemodynamic response function, as well as the six movement-related covariates (determined from the realignment procedure) as nuisance regressors. Because of excessive head movements in both scans, one subject had to be excluded from additional analysis, and thus the fMRI analysis includes 17 subjects.

To investigate cognitive-emotional interactions as a function of sleep, the analysis focused on executive and limbic regions of interest (ROIs), namely the bilateral dorsolateral PFC (DLPFC) and amygdala, respectively. DLPFC ROIs were defined as $6 \mathrm{~mm}$ spheres centered on previously published coordinates regarding $N$-back activations [peak MNI coordinates $(x, y, z)$; left, $(-44,17,25)$; right, $(36,36,28)$ (Owen et al., 2005)], whereas for the amygdala ROI, an unbiased anatomical mask was used, derived from the Automated Anatomical Labeling atlas (TzourioMazoyer et al., 2002) implemented in SPM8. Second-level (group) analysis was performed using a voxelwise small-volume-corrected fullfactorial ANOVA implemented in SPM8 (for a similar procedure, see Goldstein et al., 2013). Three factors were examined using the SPM ANOVA analysis: load (low or high), distractor type (negative or neutral), and session (sleep-rested or sleep-deprived). Results included only significant voxels within each ROI after a familywise error (FWE) correction, thresholded at $p<0.05$. Post hoc analysis included mean $\beta$ values extracted from the entire ROI for each condition.

To identify changes in functional connectivity as a function of sleep, a psychophysiological interaction (PPI) analysis was conducted separately for each session (sleep-deprived/sleep-rested) using SPM8 (Friston et al., 1997). Because PPI analysis tends to lack power (O’Reilly et al., 2012), interactions were considered significant using a lower threshold of $p<$ 0.001 uncorrected. PPI analysis examined the connectivity between the 
a

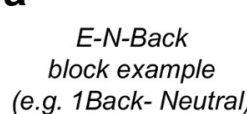

Instructions

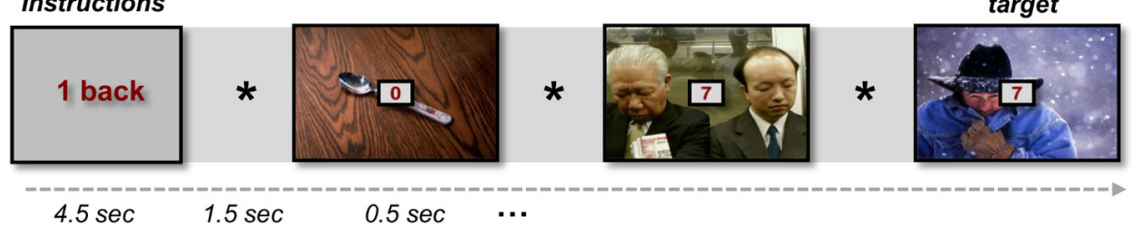

b

ssVEP

trial example

(e.g. negative distractor)

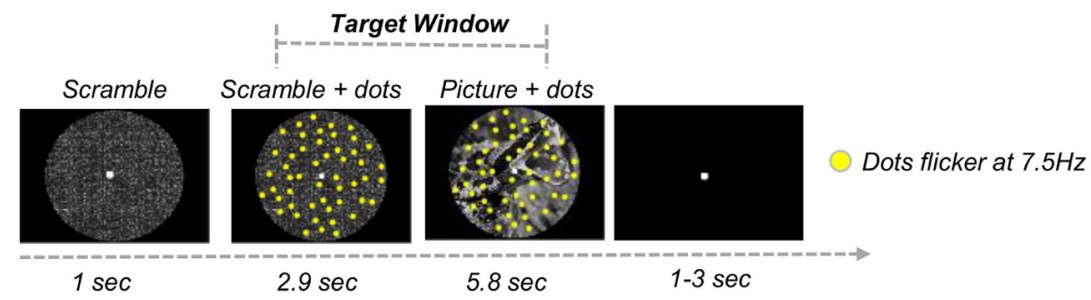

Figure 2. Study tasks. $a$, Schematic representation of an emotional $N$-back block. Each block started with load instructions (1-back or 2 back) presented for $4.5 \mathrm{~s}$, followed by rapid presentation of numbers $(0.5 \mathrm{~s}$ ) overlaid on either negative or neutral images. Each picture presentation was interleaved with an asterisk presented for $1.5 \mathrm{~s}$. Participants were asked to press a button as soon as they recognize the correct number (marked target). $\boldsymbol{b}$, Time sequence of a single trial in the ssVEP task. Each trial started with $1 \mathrm{~s}$ presentation of a scrambled picture, followed by the appearance of flickering dots (at a rate of $7.5 \mathrm{~Hz}$ ) for $2.9 \mathrm{~s}$. Consequently, a positive, negative, or neutral picture appeared for $5.8 \mathrm{~s}$ behind the dots. Targets were rare intervals of coherent motion that could only occur between 1.17 and $7 \mathrm{~s}$ after stimulus onset (marked target window). Each trial lasted $9.751 \mathrm{~s}$, with a variable $1-3 \mathrm{~s}$ intertrial interval. E-N-Back, emotional $\mathrm{N}$-back.

selected amygdala ROI and the rest of the brain during either emotional or cognitive load and was conducted as follows: an individual design matrix including three regressors was specified for each subject separately for each session (sleep-deprived/sleep-rested). The design matrix included the BOLD signal time course from the amygdala seed region, regressors coding the temporal ordering of task conditions, and, finally, a PPI term, which was the product of the deconvolved time course in the amygdala with a vector representing the order of the psychological variables of interest (high vs low load or neutral vs negative distractors in separate analyses). A second-level paired $t$ test comparing sleep-rested vs sleep-deprived conditions was then applied to PPI results. To examine the effects of session-specific amygdala connectivity patterns on task performance, these results were further correlated with behavioral measurements acquired during task performance.

ssVEP emotional distraction task. To further examine the effect of sleep on cognitive control of emotion during high perceptual load, we used an EEG task evoking ssVEPs. ssVEPs are generated in visual regions and measure neural activity elicited by task-relevant stimuli that flicker at a known rate (e.g., a flickering light). Competition by task-irrelevant distractors, such as neutral or affective images, can therefore be quantified as an attenuation of task-evoked processing, predominantly evident in visual regions. Indeed, studies have shown reduced occipital ssVEP amplitudes (evoked by flickering dots) when dots were superimposed on emotionally arousing compared with neutral images (Müller et al., 2008; Deweese et al., 2014).

The current ssVEPs were evoked using random-dot kinematograms that consisted of randomly moving dots flickering at a rapid rate (7.5 $\mathrm{Hz}$ ). In accordance with previous work, these dots were superimposed on emotional or neutral distracting pictures (Müller et al., 2008; Deweese et al., 2014). Perceptual load was achieved by the demanding task of detecting very short intervals of coherently moving dots, ignoring the distractors. This task included an additional subject $(n=19)$ who completed the crossover design but was not scanned because of technical difficulties in her SD session.

During the experiment, stimuli were presented centrally on an LED monitor, set at a resolution of $1024 \times 768$ with a refresh rate of 60 frames/s (i.e., $16.66 \mathrm{~ms}$ refresh interval). Because both positive and negative stimuli have been reported as effective distractors in previous ssVEP studies (Müller et al., 2008), our distractors were divided into three valence categories: (1) erotic couples/kittens as positive distractor categories; (2) neutral people at work/cows as neutral distractor categories; and (3) mutilated human bodies/snakes as negative distractor categories. Each valence category included 30 pictures totaling 90 pictures. Pictures were selected from the IAPS (Lang et al., 1999) with additional images, selected from the public domain to complete balanced human and ani- mal picture categories. For all IAPS images, valence and arousal ratings for neutral images were 5.34 and 3.26, for positive images were 7.04 and 5.58 , and for negative images were 2.84 and 6.39 , respectively. All picture stimuli were grayscale pictures and were controlled for visual complexity (measured as .jpeg size) and matched for luminance using scripts from the MATLAB image processing toolbox. Picture stimuli were circular in nature and were cropped and adjusted such that the defining element of each picture was positioned at the center of a circle (Fig. $2 b$ ).

Each trial began with a $1 \mathrm{~s}$ presentation of an IAPS image with individual pixels scrambled to avoid contamination of the ssVEP with transient responses to the luminance gradient created by stimulus onset. Next, a total of 150 yellow dots (each $0.3^{\circ} \times 0.3^{\circ}$ of visual angle) were superimposed on the scrambled image for $2917 \mathrm{~ms}$. The scrambled background picture was then replaced by a positive, neutral, or negative image that remained on the screen for the remaining duration of the trial (5834 $\mathrm{ms})$. Dots were distributed randomly across pictures and flickered at a rate of $7.5 \mathrm{~Hz}$, while remaining inside the circle $\left(6.9^{\circ}\right.$ visual angle) at all times. The yellow dots were "on" for six frames and "off" for eight frames. All dots remained in continuous motion throughout the trial, and each dot changed its position by $0.04^{\circ}$ in a random direction with every ssVEP cycle (i.e., 7.5 times/s).

In a random subset of $50 \%$ of the trials, all dots moved coherently in the same direction (target), and participants were instructed to respond to coherent motion events with a mouse click, as quickly and as accurately as possible. Coherent motion of the targets occurred in one of four diagonal directions $\left(45^{\circ}, 135^{\circ}, 225^{\circ}\right.$, and $\left.315^{\circ}\right)$ at random. In an effort to produce a difficult and demanding perceptual detection task, coherent motion lasted for only four successive cycles of $7.5 \mathrm{~Hz}$ (i.e., $533.33 \mathrm{~ms}$ ). Targets occurred unpredictably once (in 43 of the 90 trials) or twice (in 3 of the 90 trials) in a given trial, with the remaining 44 trials consisting of random movement of the dots. The first possible coherent motion event was at $1170 \mathrm{~ms}$ after stimulus onset and the last coherent motion event at $7000 \mathrm{~ms}$. Targets occurring during the scrambled image were not included in the behavioral analysis. Trials with dual targets were inserted to ensure that attention was directed to the task for the entire duration of the trial, and such trials were also not included in the final analysis. As a result, only single-target or no-target trials occurring during picture presentation were included in the final analysis. Each trial lasted for $9751 \mathrm{~ms}$, with interstimulus intervals varying randomly between 3000 and 5000 ms. Fixation was facilitated by presenting a white fixation dot at the center of the screen (i.e., circle). Before the experiment, all participants performed 15 practice trials to become familiar with task instructions, which included different distractors than the main experiment.

EEG recording and preprocessing. Electrophysiological data were collected from the scalp using a the BrainAmp-MR EEG amplifier (Brain 
Products) and the BrainCap electrode cap with sintered $\mathrm{Ag} / \mathrm{AgCl}$ ring electrodes providing $30 \mathrm{EEG}$ channels, one EKG channel, and one EOG channel (Falk Minow Services). The reference electrode was between $\mathrm{Fz}$ and Cz. Raw EEG was sampled at $500 \mathrm{~Hz}$ and recorded using the Brain Vision Recorder software (Brain Products) with scalp impedance for each electrode kept below $20 \mathrm{k} \Omega$. Additional processing and filtering was performed offline. Subsequently, continuous data were low-pass filtered offline at a frequency ( $3 \mathrm{~dB}$ point) of $40 \mathrm{~Hz}$ (12th order Butterworth filter with $24 \mathrm{~dB}$ /octave roll-off implemented in MATLAB) before segmenting. Single epochs of $9200 \mathrm{~ms}$ in length ( $400 \mathrm{~ms}$ before and $8800 \mathrm{~ms}$ after dot onset) were then extracted from the continuous EEG signal. Segments were inspected visually in EEGlab, and trials with ocular artifacts or with amplitudes exceeding $100 \mu \mathrm{V}$ were rejected from additional analysis. This resulted in an overall retention rate of 79.3 trials, with trial counts not significantly different (paired $t$ tests) between conditions (positive, 26.0 trials; neutral, 27.7 trials; negative, 25.6 trials on average) or experimental sessions (sleep-rested, 81.0; sleep-deprived, 77.8 trials on average).

ssVEP analysis. Time-varying amplitudes at the stimulation frequency $(7.5 \mathrm{~Hz})$ were extracted by means of a Hilbert transformation of the time-domain averaged data using in-house MATLAB scripts: data were filtered with a 10th-order Butterworth bandpass filter having a width of $0.5 \mathrm{~Hz}$ around the center frequency of 7.5. The time-varying amplitude was extracted as the complex conjugate of the bandpass-filtered signal and the Hilbert-transformed analytic signal for each time point. The temporal smearing introduced by this procedure was $440 \mathrm{~ms}$ as measured by the FWHM of the impulse response function. Subsequently, mean amplitudes were extracted across occipital electrodes $(\mathrm{O} 1, \mathrm{O} 2$, and $\mathrm{Oz})$, at a time window corresponding to distractor onset (between 3600 and $3700 \mathrm{~ms}$ ) and subtracted from the mean amplitudes of the baseline segment (the presentation of the scrambled picture, 2000-3000 ms). These values were then analyzed using a repeated-measures ANOVA examining the effect of two factors: (1) distractor valence (negative/positive/ neutral) and (2) session (sleep-rested or sleep-deprived). Main effects and interactions were tested using a significance of $p<0.05$.

In addition to time-varying amplitude, we also extracted the timevarying inter-electrode phase-locking value, calculated as the stability of the complex phase across trials (Lachaux et al., 1999), relative to the site Oz. Specifically, we used the real and imagery part of the Hilbert transform calculated for each trial, time point, and electrode to yield an index of time-varying complex phase. These instantaneous phase values were normalized by dividing in their absolute value, to eliminate amplitude bias. For each time point, we then subtracted the complex phase at electrode $\mathrm{Oz}$ from all other cranial electrodes, resulting in an electrode by time point matrix of complex difference values. These values were again normalized to be on a unit circle (dividing by their amplitude) and then averaged across the trials of a given experimental condition (for a similar procedure, see Keil et al., 2007). Resulting phase-locking indices are bounded between 0 and 1 and can be interpreted to reflect similarity of the phase difference between two electrodes across trials, at a given moment in time, with 1 indicating identity of the phase difference and 0 indicating statistical independence. To examine changes in frontal connectivity patterns across sessions, Fp1 and Fp2 phase-locking indices were analyzed using a repeated-measures ANOVA examining the effect of distractor valence (negative/positive/neutral) and session (sleeprested or sleep-deprived). To allow mapping and avoid distortions of the scale by the perfect phase locking of $\mathrm{Oz}$ with itself, the values at $\mathrm{Oz}$ itself were replaced by a weighted mean of the spline interpolated values of the remaining electrodes. However, these values did not enter statistical analysis.

\section{Results}

\section{Effect of SD on sleepiness and mood}

As expected, SD was associated with an increase in both subjective and objective assessments of sleepiness, as measured by SSS and PVT, respectively. Both scores were increased significantly in the sleep-deprived compared with sleep-rested sessions (measured at 7:00 A.M. of each session; SSS, mean \pm SD of $2.18 \pm 1.01$ to $4.65 \pm 1.37$; PVT, mean \pm SD of $2.94 \pm 2.49$ to $10.06 \pm 6.86$; both $p<0.0005$ ) and across the SD night (measured at 11:00 P.M. and 7:00 A.M. of the SD session; SSS, mean \pm SD of $2.06 \pm$ 0.66 to $4.65 \pm 1.37$; PVT, mean \pm SD of $2.88 \pm 2.37$ to $10.06 \pm$ 6.86 ; both $p<0.0005)$. These findings demonstrate that the SD process was effective and participants were indeed tired after the SD night.

Participants' mood was also impaired by SD, as assessed by both the PANAS and VAS mood scores. VAS scores were decreased significantly after SD compared with the sleep-rested session (measured at 7:00 A.M. of each session, mean \pm SD of $8.14 \pm 1.01$ to $6.22 \pm 1.86 ; p<0.0008$ ) and across the SD night (measured at 11:00 P.M. and 7:00 A.M. of the SD session, mean \pm $\mathrm{SD}$ of $8.3 \pm 1.2$ to $6.22 \pm 1.86 ; p<0.00005)$. PANAS scores revealed a significant decline only in the positive scale (measured at 7:00 A.M. of each session, mean \pm SD of $2.89 \pm 0.64$ to $1.94 \pm$ 0.94; $p<0.000005$ and at 11:00 P.M. and 7:00 A.M. of the SD session, mean $\pm \mathrm{SD}$ of $3 \pm 0.62$ to $1.94 \pm 0.94 ; p<0.00005)$ without a significant change in the negative scale.

\section{Effect of SD on behavioral results}

For the emotional $\mathrm{N}$-back task, participants' correct responses and reaction times were analyzed using ANOVA, with the factors load (high/low), session (sleep-rested/sleep-deprived), and distractor type (neutral/negative). Consistent with previous findings, accuracy scores declined after SD (mean \pm SD, $98 \pm 0.01 \%$ correct vs $\left.94.5 \pm 0.04 \% ; F_{(1,16)}=11.44, p<0.005\right)$. There were no main effects or interactions of accuracy scores with distractor type. However, reaction times were slower for neutral distractors $\left(\right.$ mean $\pm \mathrm{SD}, 0.64 \pm 0.14$ vs $\left.0.61 \pm 0.15 \mathrm{~s} ; F_{(1,16)}=7, p<0.02\right)$ and for low load conditions (mean $\pm \mathrm{SD}, 0.65 \pm 0.13$ vs $0.6 \pm$ $\left.0.13 \mathrm{~s} ; F_{(1,16)}=7, p<0.02\right)$.

For the ssVEP task, because of uneven numbers of accurate responses in each category, the positive and negative categories were combined to an affective category and the reaction time data were not analyzed. Accuracy data were analyzed using ANOVA, with the factors session (sleep-rested/sleep-deprived) and distractor type (neutral/affective). An accurate response was classified by the following: $\mathrm{A}$, it was a target trial; $\mathrm{B}$, reaction time was at least $150 \mathrm{~ms}$; and $\mathrm{C}$, the picture (and not the scrambled image) was in the background during the period of coherent motion. Results revealed a decline in accuracy scores after SD (mean \pm $\mathrm{SD}, 72.28 \pm 3.4 \%$ correct vs $49.1 \pm 4.5 \% ; F_{(1,16)}=17.37, p<$ $0.005)$, demonstrating accuracy scores at chance levels after SD. In addition, accuracy scores were higher during neutral compared with affective distractors (mean $\pm \mathrm{SD}, 69.14 \pm 3.9 \%$ correct vs $\left.52.24 \pm 3.7 \% ; F_{(1,16)}=11.93, p<0.005\right)$. Accuracy scores of both tasks are depicted in Figure 3.

\section{Effect of SD on fMRI activity}

First, we examined the effect of SD on neural processing within bilateral DLPFC and amygdala separately, using a small-volumecorrection full-factorial ANOVA including the factors session (sleep-rested/sleep-deprived), load (high/low), and distractor type (neutral/negative). An expected main effect of load was observed in the bilateral DLPFC (Fig. $4 a ; p<0.05$ FWE corrected). Complementary mean $\beta$ values extracted from the entire DLPFC ROIs replicated this finding and confirmed a main effect of load (for the right DLPFC, $F_{(1,16)}=29.28$; for the left DLPFC, $F_{(1,16)}=$ 11.6; both $p<0.005)$ and a significant session $\times$ distractor interaction in right DLPFC activity $\left(F_{(1,16)}=6.23, p<0.05\right)$. Post hoc analyses revealed that right DLPFC activity was greater during neutral compared with negative distractors only after SD $\left(t_{(16)}=\right.$ 
a

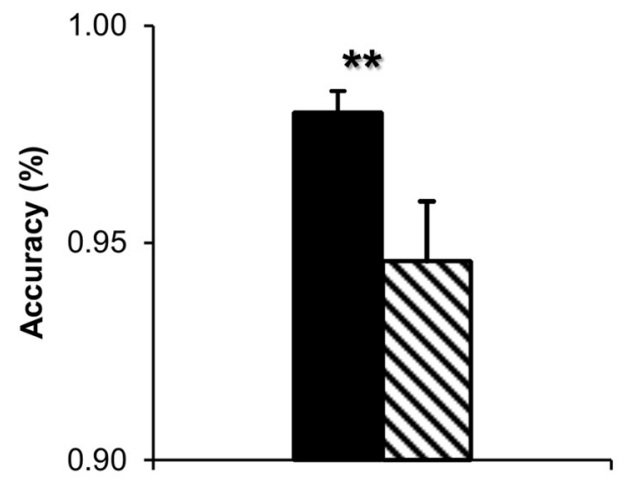

b

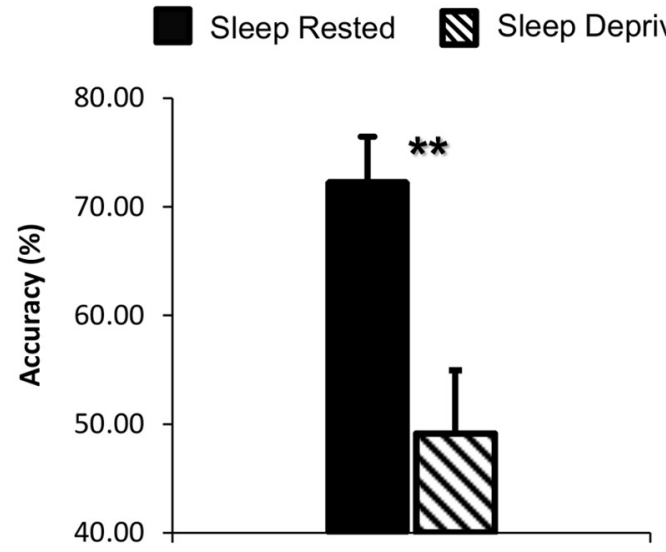

Neutral distractor

Affective distractor

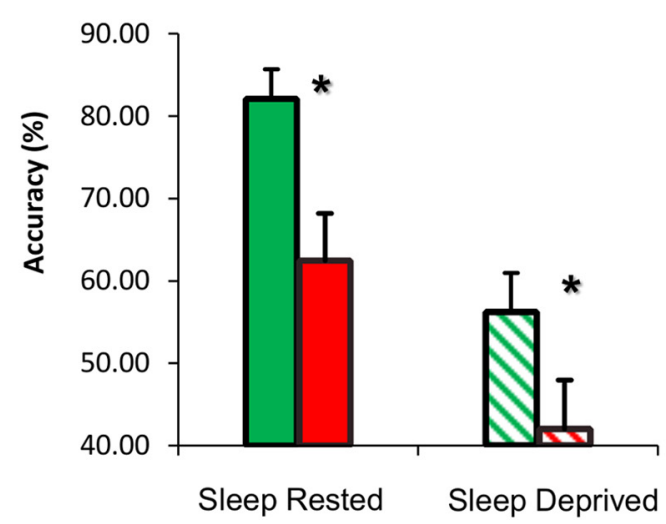

Figure 3. Behavioral accuracy results. $\boldsymbol{a}$, Bar graphs displaying ANOVA main effect of session (sleep-deprived/sleep-rested) in emotional $N$-back accuracy scores. There were no main effects or interactions of accuracy scores with distractor type. $\boldsymbol{b}$, Bar graphs displaying ANOVA main effect of session (sleep-deprived/sleep-rested) and main effect of distractor (neutral/affective) in ssVEP accuracy scores. Results revealed a decline in accuracy scores to chance level after SD. Error bars represent SEM. ${ }^{*} p<0.05 ;{ }^{* *} p<0.005$.

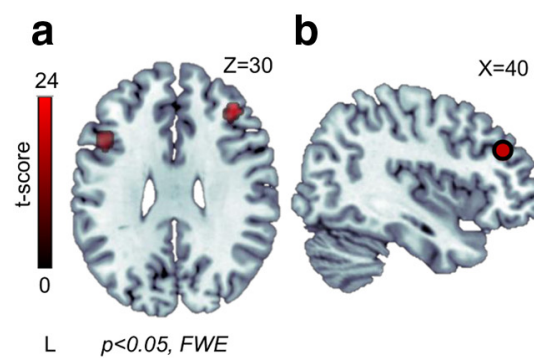

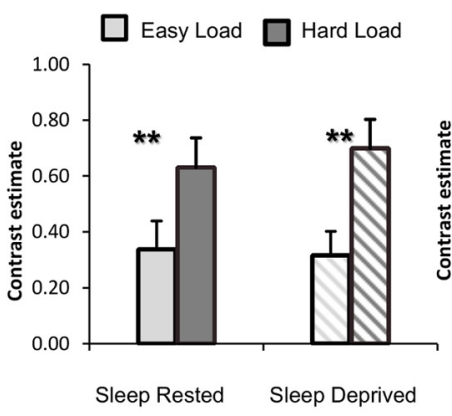

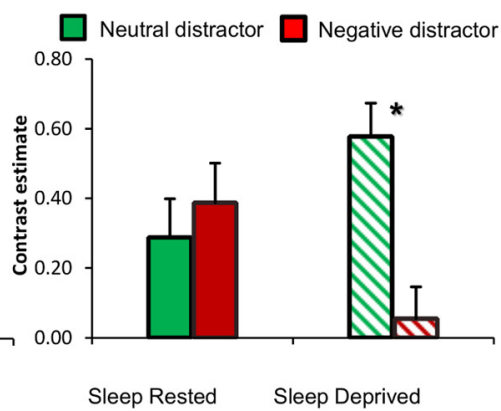

Figure 4. Right DLPC activity. $\boldsymbol{a}$, An axial slice displaying ANOVA main effect of load (low/high load) from the voxelwise ROl analysis in the bilateral DLPFC across all distractor types (negative, neutral) and sleep states (deprived, rested) [peak MNI coordinates $(x, y, z)$; left, $(-45,20,28)$; right, $(39,35,31)]$. $p<0.05$, FWE corrected. $\boldsymbol{b}$, Right DLPFC ROI mask (left brain image) and corresponding average activity across loads (left bar graph) and distractors (right bar graph). Distractor activity was derived during low load conditions. Error bars represent SEM. ${ }^{*} p<0.05 ;{ }^{* *} p<0.005$.

2.08, $p=0.05)$ and not during the sleep-rested session $\left(t_{(16)}=\right.$ $0.02, p>0.7)$. Interestingly, the reported increase in processing neutral distractors was primarily evident during low load conditions $\left(t_{(16)}=2.3, p<0.05\right)$ and not during high load $\left(t_{(16)}=\right.$ $-0.38, p>0.7$ ). These findings (depicted in Fig. 4) suggest that SD induced a significant change in right DLPFC activity, introducing an increased influence of neutral distractors during task performance that was not present in sleep-rested conditions.

For the amygdala, ANOVA revealed a main effect of session in the left amygdala (Fig. 5a; $p<0.05$ FWE corrected; no significant effects found within the right amygdala), with SD amplifying left amygdala activity, regardless of load or distractor type. The left amygdala further revealed a load $\times$ session interaction $(p<0.05$ FWE corrected), detailed below. Complementary mean $\beta$ values extracted from the entire left amygdala ROI replicated these findings and confirmed a main effect of session $\left(F_{(1,16)}=12.8, p<\right.$ $0.005)$ and a load $\times$ session interaction $\left(F_{(1,16)}=11.63\right.$, $p<0.005)$. Post hoc analyses revealed that, although in the sleep-rested session the left amygdala demonstrated a contextspecific decrease during high compared with low load $\left(t_{(16)}=\right.$ $4, p<0.005)$, such modulation was absent after SD, with similar activity revealed for both high and low load conditions $\left(t_{(16)}=0.55, p>0.5\right)$. In accordance, ROI-based analyses further revealed a main effect of load $\left(F_{(1,16)}=6.8, p<\right.$ 

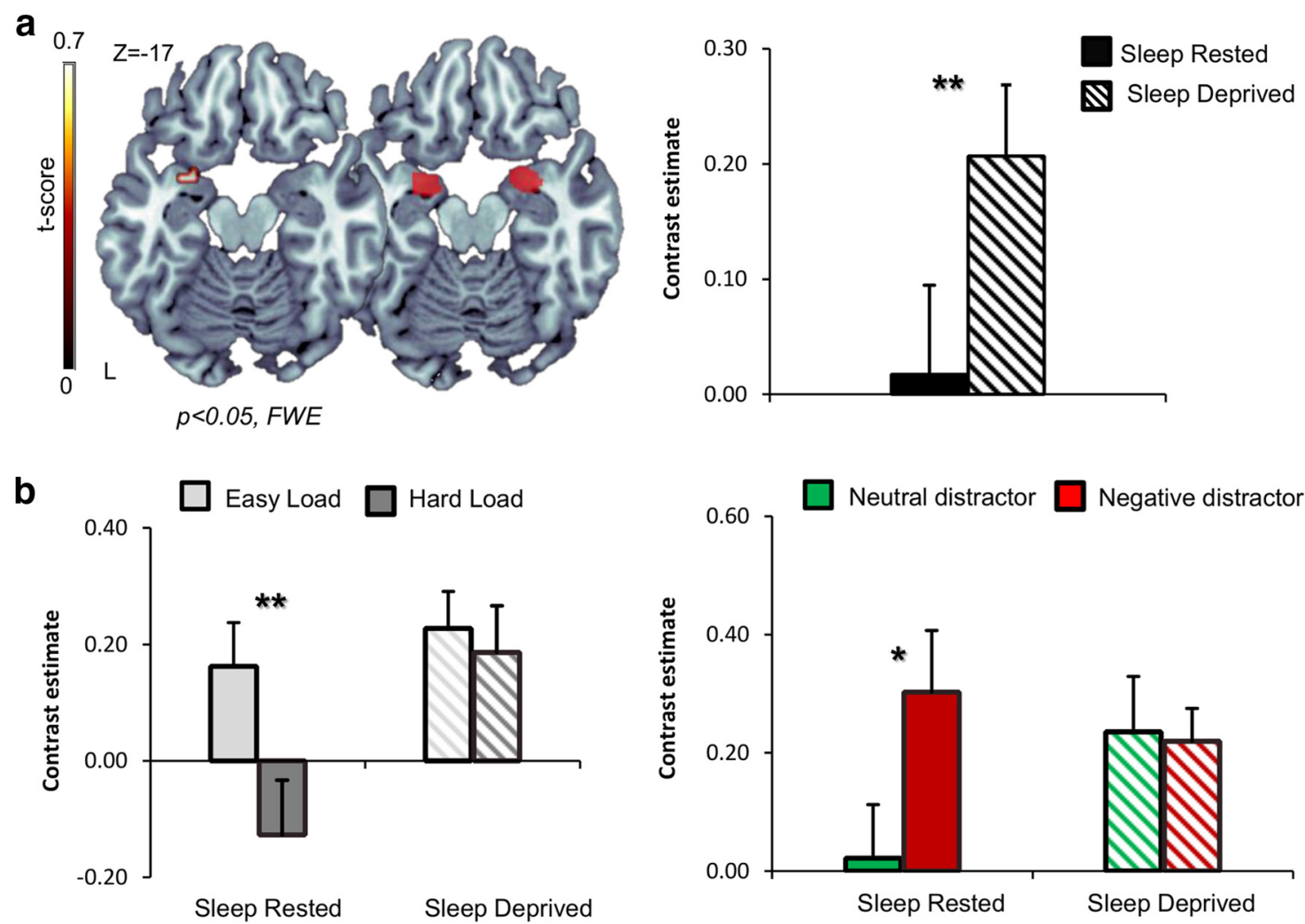

Figure 5. Left amygdala activity. $\boldsymbol{a}$, Brain maps displaying ANOVA main effect of session (sleep-deprived/sleep-rested; left brain image) in the left amygdala [ $p<0.05 \mathrm{FWE}$ corrected; peak MNI coordinates $(x, y, z)$ : left, $(-33,2,-20)]$ derived from the voxelwise ROl analysis in bilateral amygdala (ROl mask presented in the right brain image). No significant main effect of session was observed in the right amygdala at $p<0.05$, FWE corrected. Main effect of session is further illustrated using average activity across the entire left amygdala ROl (left bar graph). $\boldsymbol{b}$, Bar graphs illustrate the difference in contrast estimates across load (left side) and distractor (right side) conditions averaged across the left amygdala Rol. Distractor activity was derived during low load conditions. Error bars represent SEM. ${ }^{*} p<0.05 ;{ }^{* *} p<0.005$.

0.02), demonstrating increased left amygdala activity during low compared with high load conditions across sessions. These results are depicted in Figure 5.

Using mean $\beta$ values extracted from the entire left amygdala ROI, we further examined the effects of distractor type on left amygdala activity. This analysis revealed a significant increase in amygdala activity in response to neutral distractors after SD compared with the sleep-rested session $\left(t_{(16)}=-2.9, p<0.05\right)$. We further examined the response to distractors separately for low versus high load conditions within the left amygdala to examine load-specific modulation of emotional processing known to occur during cognitive-emotional interactions (Okon-Singer et al., 2013). This analysis revealed that, in the low load conditions, the left amygdala demonstrated a typical increase during the presentation of negative compared with neutral distractors only in the sleep-rested session $\left(t_{(16)}=-2.4, p<0.05\right.$; Fig. $5 b$; notably, this effect was also evident for the right amygdala, $t_{(16)}=-2.18, p<$ $0.05)$. After SD, amygdala activity no longer differentiated between distractors, responding equally to both neutral and negative distractors $\left(t_{(16)}=0.1\right.$; for the right amygdala, $t_{(16)}=-0.38$, both $p>0.7$ ). During high load conditions, left amygdala activity demonstrated a significant increase to both distractors after SD compared with sleep-rested conditions $\left(t_{(16)}=-2.55\right.$ for negative distractors, $t_{(16)}=-2.4$ for neutral distractors, both $p<$ $0.03)$. Altogether, these findings suggest that $\mathrm{SD}$ disabled valance or load discrimination in left amygdala activity.

Effect of SD on fMRI connectivity and relation to behavior To further examine whether impaired discrimination in left amygdala activity could be a result of frontal dysregulation, we analyzed left amygdala connectivity using PPI as a function of cognitive load (high $>$ low load) and emotional load (neutral $>$ negative distractors). Results reveal that, during high compared with low cognitive load, the left amygdala was connected to the left anterior cingulate cortex (ACC) only during the sleep-rested session but not after SD $(p<0.0005$ uncorrected, minimum of five voxels). Furthermore, the change in ACC-amygdala connectivity was significantly correlated with the decrease in accuracy scores after SD $(r=0.63, p=0.007)$. These results are depicted in Figure 6. A change in frontal connectivity was also evident during PPI analysis of neutral compared with negative distractors (examined during low load conditions). Similar to the previous analysis, left amygdala connectivity with the bilateral middle frontal gyrus was observed only during sleep-rested conditions and not after SD $(p<0.001$ uncorrected, minimum of five voxels). These findings suggest that a lack of frontal modulation is associated with impaired amygdala ability to discriminate between aspects of load or valence without sleep.

Last, to assess the protective role of REM sleep on cognitive control of emotion, percentage REM sleep amounts recorded at the night of the sleep-rested session (see Materials and Methods) were correlated with the change in amygdala-ACC connectivity during sleep-rested compared with SD sessions. Results reveal a significant negative correlation between percentage REM sleep amount and amygdala-ACC connectivity $(r=-0.53, p<0.03$; Fig. $6 b$ ), demonstrating that lower amounts of REM sleep were associated with a greater decline in amygdala modulation after SD. Notably, this correlation was mostly driven by sleep-rested amygdala-ACC connectivity $(r=-0.44, p=0.07)$ and not by 

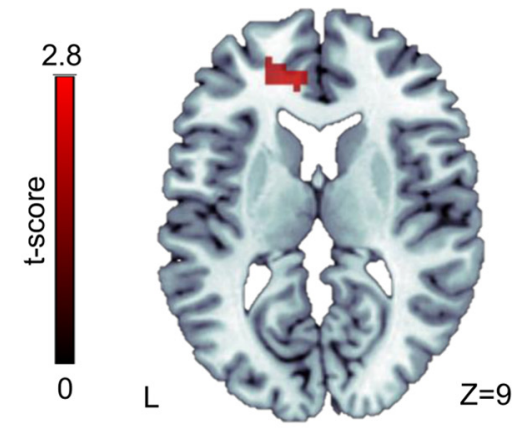

$P<0.0006$, min 8 voxels

b

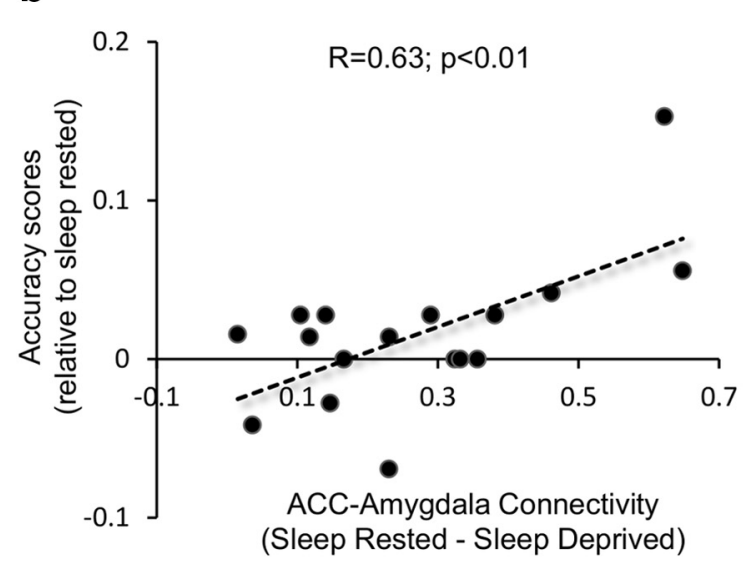

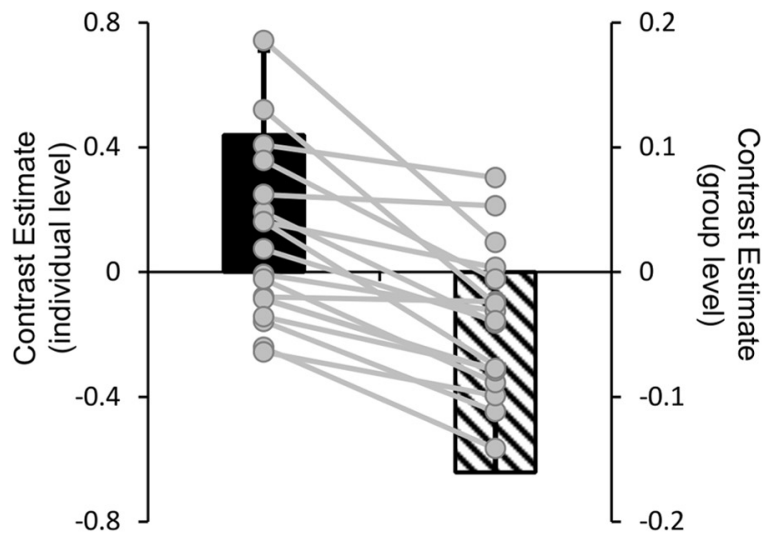

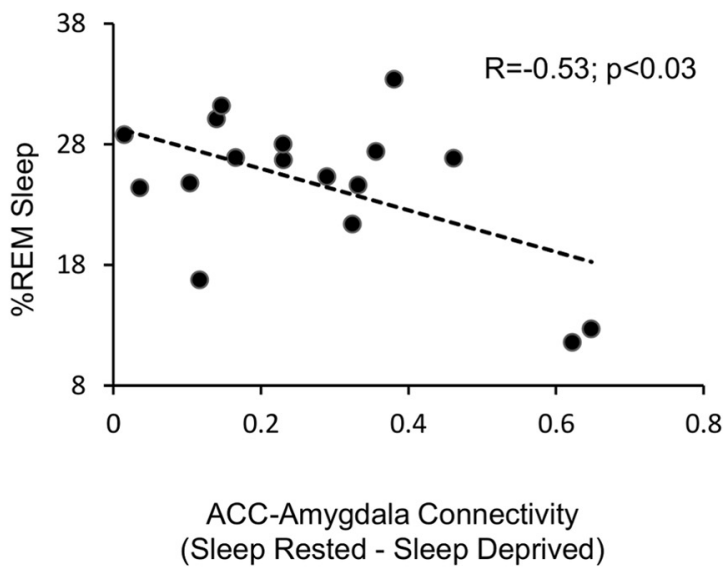

Figure 6. Left amygdala connectivity. $\boldsymbol{a}$, An axial slice displaying activation of the ACC as derived from PPI analysis of left amygdala connectivity during high $>$ low load, in sleep-rested versus sleep-deprived sessions [peak MNI coordinates $(x, y, z),(-9,44,10)$; left brain image, $p<6 \mathrm{E}-4$ uncorrected, minimum of 8 voxels]. Corresponding graphs (top right) display ACC activity for both group levels (bar graph) and individual levels (circles; note the different scale). Error bars represent SEM. $\boldsymbol{b}$, Scatter plots displaying the relationship between ACC -amygdala connectivity and relative accuracy scores (bottom left) and percentage REM sleep (bottom right).

$\mathrm{SD}(r=-0.11, p>0.5)$, supporting the immediate effect of REM sleep on cognitive control of emotion. In addition, neither light nor deep sleep amounts were found to be correlated with amygdala-ACC connectivity (both correlations $p>0.28$ ), reflecting the critical role of REM sleep in overnight emotional processing.

\section{Effect of SD on ssVEP amplitudes and connectivity}

The flickering dots reliably evoked steady-state responses at the expected frequency of $7.5 \mathrm{~Hz}$ across both sessions, with the greatest overall ssVEP amplitudes occurring in electrode $\mathrm{Oz}$ and its nearest neighbors in accordance with previous work (Müller et al., 2008). Furthermore, distractor onset was associated with a marked decrease of ssVEP amplitudes as shown in Figure $7 a$, in both sleep-rested and SD sessions. The grand meantime-varying energy of the signal over occipital electrodes, as quantified by the Hilbert transform, was used to calculate the amplitude decrease (relative to scramble) elicited by distractor onset, across three occipital electrodes $(\mathrm{O} 1, \mathrm{O} 2$, and $\mathrm{Oz}$ ). These values were then analyzed using a repeated-measures ANOVA examining the effect of two factors: (1) distractor valence (negative/positive/ neutral); and (2) experimental session (sleep-rested or sleepdeprived). The results demonstrated a main effect of distractor type $\left(F_{(2,17)}=3.7, p<0.05\right)$ and an interaction of session $\times$ distractor type $\left(F_{(2,17)}=4.5, p<0.05\right)$. Post hoc analyses revealed that, similar to the emotional $N$-back task, negative distractors induced a greater decrease compared with neutral only during sleep-rested sessions $\left(t_{(18)}=5.15, p<0.0001\right)$. After SD, a similar response was observed for both neutral and negative distractors $\left(t_{(18)}=-0.17, p>0.5\right)$. These findings suggest that valencespecific modulation of primary visual areas was also impaired by $\mathrm{SD}$ introducing a bias toward negative stimuli for all distractor types.

To further examine whether such impaired discrimination could be a result of frontal dysregulation, we analyzed $\mathrm{Oz}$ phaselocking indices with frontal electrodes ( Fp1 and Fp2) separately for sleep-rested and SD sessions. These indices were examined using a repeated-measures ANOVA including the factors distractor valence (negative/positive/neutral), electrode (Fp1 and Fp2), and session (sleep-rested or sleep-deprived). Results reveled a main effect of session $\left(F_{(1,18)}=5.7, p<0.05\right)$, demonstrating a significant decrease in $\mathrm{Oz}$-frontal connectivity after SD (Fig. 8a). In accordance with the emotional $\mathrm{N}$-back results, this finding suggests an association between impaired frontal regulation and loss of emotional discrimination without sleep.

Last, to assess the protective role of REM sleep on emotion modulation as well, we examined the correlation between percentage REM sleep and the change in frontal phase-locking indices during sleep-rested compared with sleep-deprived sessions. The results revealed a significant negative correlation between 
a

Sleep Rested session
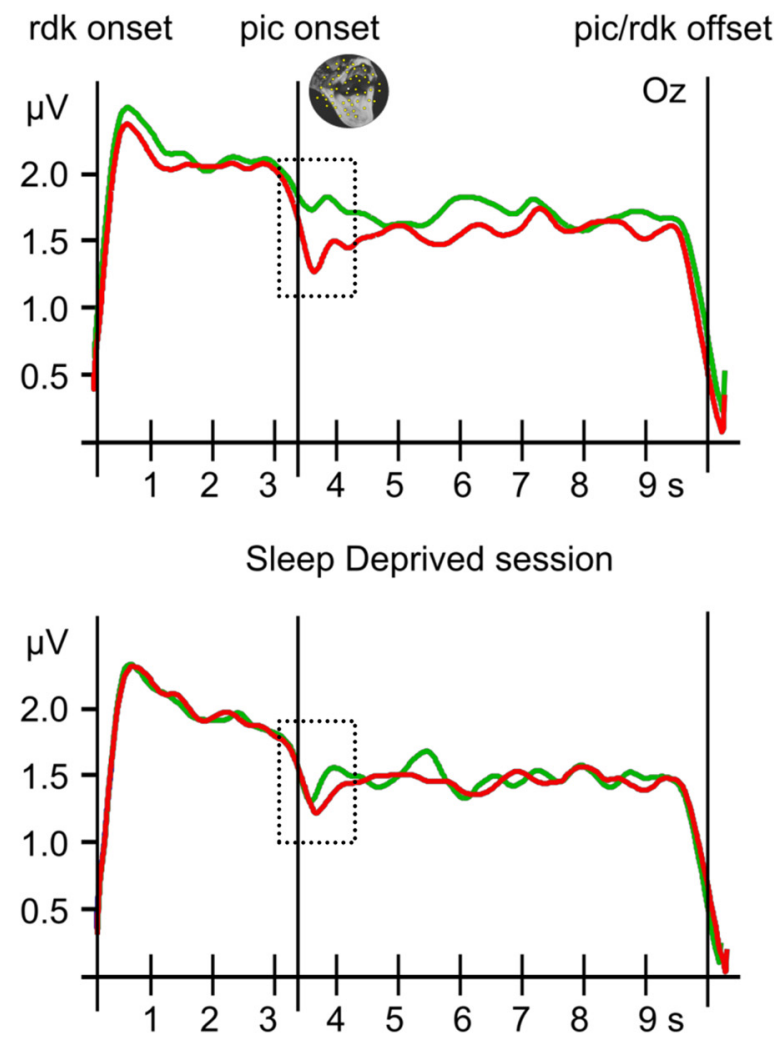

b $\square$ Neutral distractor $\square$ Negative distractor

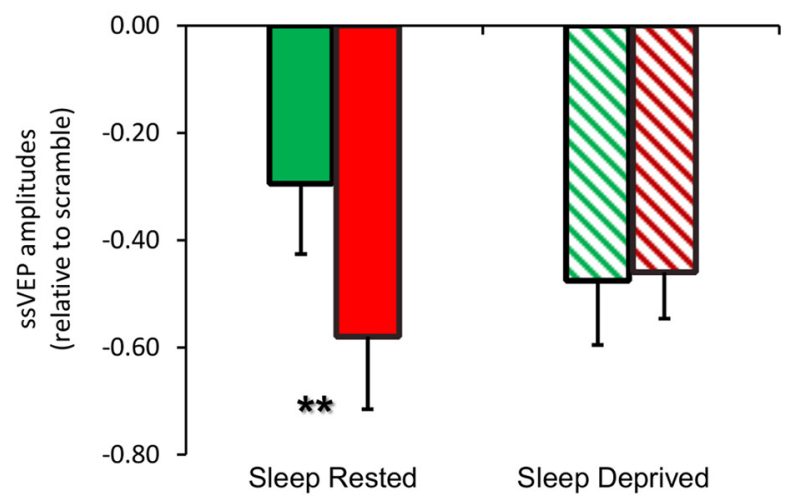

Figure 7. SsVEP amplitudes. $\boldsymbol{a}$, Time course of sSVEP amplitudes in the chosen frequency domain obtained by complex demodulation averaged across all subjects in a subset of posterior electrodes $(01,02,0 z)$. A dashed vertical box indicates the time window of significant amplitude reduction for negative compared with neutral distractors. $\boldsymbol{b}$, Bar graphs illustrate the corresponding ANOVA distractor $\times$ session interaction revealing a marked change in processing neutral distractors, only after SD. Error bars represent SEM. ${ }^{* *} p<0.0005$. rdk, random-dot kinematograms.

percentage REM and frontal connectivity $(r=-0.53, p<0.03$; Fig. $8 b$ ), demonstrating again that a lower amount of REM sleep is associated with a greater decline in frontal modulation of emotional processing.

\section{Discussion}

Our findings demonstrate that sleep loss significantly impairs cognitive control of emotion, leading to increased processing of distracting neutral information, coupled with a significant de- crease in frontal connectivity, evident in both EEG and fMRI signals. Interestingly, both limbic and early perceptual regions lacked neural discrimination between neutral and affective stimuli after SD, exhibiting a significant increase in the response to neutral distractors and not necessarily an increased effect of emotional distractors. Moreover, context-dependent modulation of central emotional processing was disabled by $\mathrm{SD}$, resulting in similar amygdala activation in response to all cognitive loads and distractor types. These findings imply that SD might induce a general decrease in the threshold for emotional activation, probably associated with decreased frontal regulation. Furthermore, this decrease was associated with lower amounts of REM sleep, supporting a role for REM in regulating emotional reactivity (Gujar et al., 2011a; van der Helm et al., 2011) possibly via renormalization of emotional thresholds.

Using cognitive load to modulate emotional processing, previous studies revealed a reduction in perceptual and affective processing during high compared with low cognitive load (Pessoa et al., 2002; Van Dillen et al., 2009). For instance, the amygdala displayed less activity in response to affective distractors during high compared with low cognitive load (Erk et al., 2007; Okon-Singer et al., 2014) and differentiated between neutral and affective distractors only during low cognitive loads (Blair et al., 2007). Our findings replicate these effects during the sleep-rested session, revealing a decrease in amygdala activity during high load and intact distractor differentiation only during low load.

Such context-specific modulations in amygdala activity have been explained by either lowered top-down inhibition of distractor processing during high cognitive load or bottom-up limited resources attributable to cognitive task demands (for reviews, see Pessoa, 2008; Iordan et al., 2013; Okon-Singer et al., 2013; Pourtois et al., 2013). Interestingly, SD offers a unique way to examine such hypotheses by focusing on the effect of load manipulation on emotional processing. An effect of SD on resource availability would lead to reduced distractor processing regardless of cognitive load, while impaired inhibitory control would produce the opposite pattern, displaying increased distractor processing in both loads. In accordance with the latter, we demonstrate uniquely that SD results in increased response to both distractors, associated with a lack of neural discrimination between aspects of emotional valence and cognitive load, thus eliminating all context-dependent modulation in amygdala activity.

Lack of cognitive load differentiation in amygdala activity could be anticipated in light of a well described prefrontal vulnerability to sleep loss (Muzur et al., 2002). Indeed, numerous tasks involving PFC activity have been reported to be sensitive to the effects of total SD, including general executive function (Nilsson et al., 2005), decision making (Killgore et al., 2006), divided attention (Drummond et al., 2001), and working memory (Turner et al., 2007). A reduction in amygdala-ACC connectivity after SD further suggests a loss of cognitive control (Miller and Cohen, 2001). In other words, sleep loss may impair cognitive load differentiation simply by disrupting executive function.

However, loss of distractor discrimination is slightly more surprising. Given previous evidence of amygdala hyperactivity after SD (Yoo et al., 2007), we assumed greater activation in response to the emotional distractors after SD, while keeping distractor differentiation intact. Nevertheless, both our tasks revealed a complete lack of distractor discrimination after SD and a significantly greater response to the neutral and not the emotional distractor. An emotional bias toward neutral stimuli is common in several affective disorders [e.g., depression (Lep- 

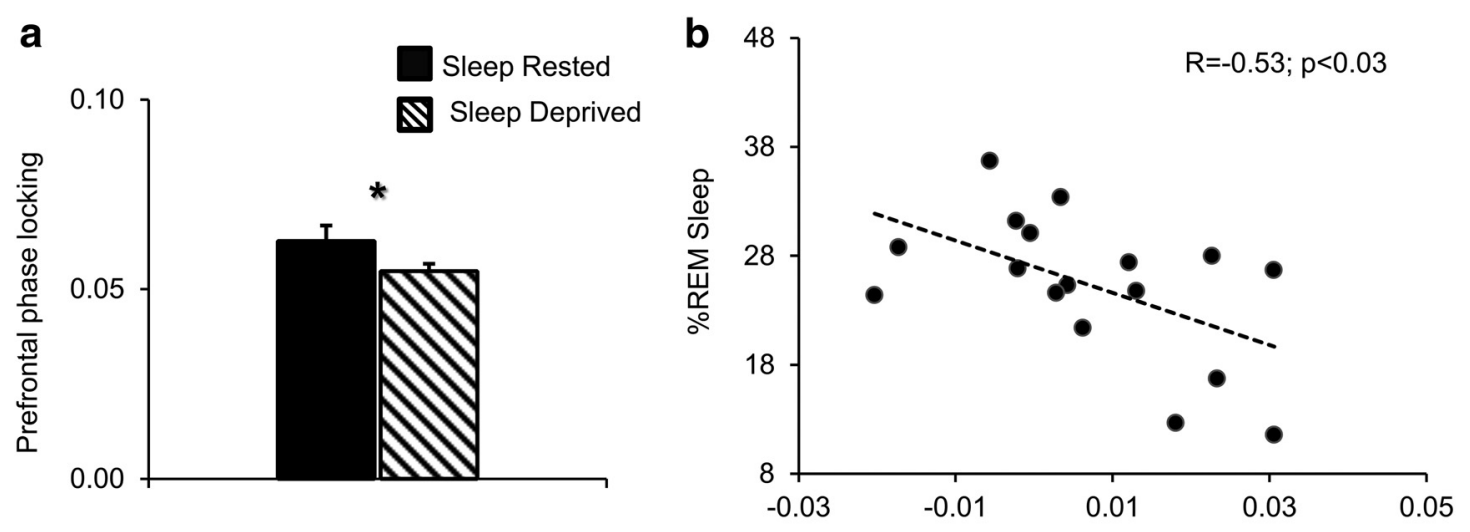

Sleep Rested - Sleep Deprived prefrontal phase locking

Figure 8. SsVEP connectivity. $\boldsymbol{a}$, ssVEP prefrontal phase-locking indices (calculated relative to $0 z$ ) in sleep-rested and sleep-deprived sessions. $\boldsymbol{b}$, A scatter plot displaying the negative correlation between percentage REM sleep and relative phase-locking decreases after SD. Error bars represent SEM. ${ }^{*} p<0.05$.

pänen et al., 2004) and social anxiety disorder (Singer et al., 2012)], further found to be correlated with state anxiety in social anxiety patients (Cooney et al., 2006) and in healthy controls (Somerville et al., 2004). Therefore, emotional processing of neutral stimuli could mediate the increased anxiety reported in healthy controls after SD (Minkel et al., 2012) and point to a significant reduction in the threshold for emotional activation.

These findings may further suggest that neutral stimuli could be regarded as emotionally ambiguous (Cooney et al., 2006), with their processing dependent on intact cognitive control of emotion. If so, processing of neutral stimuli could shift toward emotional saliency as the threshold for limbic activation is altered by sleep loss. In accordance, studies have reported an increased negative bias of neutral images during subjective emotional ratings after SD (Yoo et al., 2007), without an effect on the ratings of negative or pleasant images (Daniela et al., 2010). Although processing of neutral stimuli is sensitive to sleep loss, processing of negative stimuli reveals a relative resilience to SD. For instance, $36 \mathrm{~h}$ of SD impaired encoding of positive and neutral declarative memories without a significant effect on negative memory encoding (Walker and van der Helm, 2009). Using low and high stressors, a recent study further demonstrated increased subjective stress and anxiety only after exposure to the low-stressor condition in the SD group compared with rested controls, whereas the high-stressor condition elevated stress equally for both groups (Minkel et al., 2012). These findings suggest that negative stimuli might produce a ceiling effect in emotional activity that is relatively resilient to impaired cognitive control of emotion elicited by SD.

In addition to limbic activity, SD induced a significant change in task-related regions (right DLPFC activity in the emotional $N$-back task and primary visual cortex in the ssVEP task) during processing of neutral distractors. An increased response to neutral stimuli in the DLPFC has been reported previously, although only when affective parameters were task relevant (Perlstein et al., 2002). After SD, it was evident for irrelevant distractors only during low load conditions, again suggesting that loss of cognitive control of emotion mostly effects the lower threshold of emotional/cognitive processing while relatively sparing the high demanding conditions (i.e., negative distractor/high load, respectively). Similar to known adverse effects of SD on monotonous tasks (Lim and Dinges, 2008), it seems that low load, emotionally ambiguous conditions are also most susceptible to sleep loss.
Such an encompassing effect of SD on the threshold for emotional activation, expressed in both limbic and task-related regions, could imply the involvement of PFC dysregulation. As mentioned above, the PFC is particularly vulnerable to sleep loss, and its medial regions are known to play a key role in emotion regulation via top-down modulation of limbic regions, such as the amygdala (Davidson, 2002; Sotres-Bayon et al., 2004). In accordance with previous work (Yoo et al., 2007; Walker and van der Helm, 2009; Goldstein et al., 2013), both our tasks revealed a significant decrease in prefrontal connectivity after SD, with fMRI results implicating lateral and medial PFC, both of which are acknowledged as critical in regulating amygdala activity (for review, see Kim et al., 2011), especially during emotionregulation tasks (Banks et al., 2007). In accordance, impaired reappraisal of negative stimuli has been associated with poor sleep quality (Mauss et al., 2013) recently, suggesting that explicit attempts to exercise emotional control are also susceptible to sleep loss, though this topic still remains a fruitful target for future research. Altogether, these findings suggest that diminished PFC regulation might be associated with increased emotional reactivity after $\mathrm{SD}$.

Interestingly, we further found that these decreases in frontal connectivity were associated with lower amounts of REM sleep, shown consistently to be involved in emotional processing during sleep (Nishida et al., 2009; Gujar et al., 2011a; van der Helm et al., 2011). For instance, Payne et al. (2012) have demonstrated that higher recognition of emotional (compared with neutral) events after sleep is specifically correlated with higher REM sleep amounts, supporting a critical role for REM sleep in maintaining emotional selectivity. In accordance, our findings reveal a significant negative correlation between percentage REM sleep amount and frontal indices of emotional control, mirroring the importance of REM sleep to maintained emotional discrimination. Recent models have suggested that the unique physiology of REM sleep (i.e., minimal noradrenergic activity) enables overnight restoration of noradrenergic tone, optimally modulating both amygdala and PFC activations in response to emotionally salient events (Goldstein and Walker, 2014). In accordance with our findings, the authors further suggest, that without the beneficial effect of REM sleep, high noradrenergic tone would result in poor salience detection, leading to impaired discrimination between emotionally salient and non-salient events, associated with reduced PFC modulation of amygdala activity. Therefore, REM sleep might be involved in the calibration of emotional activity 
thresholds, enabling adaptive discrimination of emotional and neutral stimuli.

To conclude, our findings demonstrate impaired cognitive control of emotion after SD, manifested by a loss of contextdependent emotional processing and emotional discrimination, diminished frontal connectivity associated with reduced REM sleep amounts, and poorer task performance. Considering attentional and affective regulation as an integrated system serving an organism's adaptability (Thayer and Lane, 2000), the poor response to contextual demands and an exaggerated response to neutral stimuli represent a dysfunction of attentional and affective processing that substantially disrupt an appropriate response to environmental demands. Altogether, it can be suggested that $\mathrm{SD}$, possibly via impaired frontal regulation and loss of REM sleep, shifts the threshold for emotional activity to a lower set point, leading to the familiar "all too emotional" feeling of sleepless nights.

\section{References}

Anderson C, Platten CR (2011) Sleep deprivation lowers inhibition and enhances impulsivity to negative stimuli. Behav Brain Res 217:463-466. CrossRef Medline

Banks SJ, Eddy KT, Angstadt M, Nathan PJ, Phan KL (2007) Amygdalafrontal connectivity during emotion regulation. Soc Cogn Affect Neurosci 2:303-312. CrossRef Medline

Bar A, Pillar G, Dvir I, Sheffy J, Schnall RP, Lavie P (2003) Evaluation of a portable device based on peripheral arterial tone for unattended home sleep studies. Chest 123:695-703. CrossRef Medline

Blair KS, Smith BW, Mitchell DG, Morton J, Vythilingam M, Pessoa L, Fridberg D, Zametkin A, Sturman D, Nelson EE, Drevets WC, Pine DS, Martin A, Blair RJ (2007) Modulation of emotion by cognition and cognition by emotion. Neuroimage 35:430-440. CrossRef Medline

Bresler M, Sheffy K, Pillar G, Preiszler M, Herscovici S (2008) Differentiating between light and deep sleep stages using an ambulatory device based on peripheral arterial tonometry. Physiol Meas 29:571-584. CrossRef Medline

Chuah LY, Dolcos F, Chen AK, Zheng H, Parimal S, Chee MW (2010) Sleep deprivation and interference by emotional distracters. Sleep 33:13051313. Medline

Cooney RE, Atlas LY, Joormann J, Eugène F, Gotlib IH (2006) Amygdala activation in the processing of neutral faces in social anxiety disorder: Is neutral really neutral? Psychiatry Res 148:55-59. CrossRef Medline

Davidson RJ (2002) Anxiety and affective style: role of prefrontal cortex and amygdala. Biol Psychiatry 51:68-80. CrossRef Medline

Deweese MM, Bradley MM, Lang PJ, Andersen SK, Müller MM, Keil A (2014) Snake fearfulness Is associated with sustained competitive biases to visual snake features: hypervigilance without avoidance. Psychiatry Res 219:329-335. CrossRef Medline

Drummond SP, Gillin JC, Brown GG (2001) Increased cerebral response during a divided attention task following sleep deprivation. J Sleep Res 10:85-92. CrossRef Medline

Drummond SP, Bischoff-Grethe A, Dinges DF, Ayalon L, Mednick SC, Meloy MJ (2005) The neural basis of the psychomotor vigilance task. Sleep 28:1059-1068. Medline

Eftekhari A, Zoellner LA, Vigil SA (2009) Patterns of emotion regulation and psychopathology. Anxiety Stress Coping 22:571-586. CrossRef Medline

Erk S, Kleczar A, Walter H (2007) Valence-specific regulation effects in a working memory task with emotional context. Neuroimage 37:623-632. CrossRef Medline

Franzen PL, Buysse DJ, Dahl RE, Thompson W, Siegle GJ (2009) Sleep deprivation alters pupillary reactivity to emotional stimuli in healthy young adults. Biol Psychol 80:300-305. CrossRef Medline

Friston KJ, Buechel C, Fink GR, Morris J, Rolls E, Dolan RJ (1997) Psychophysiological and modulatory interactions in neuroimaging. Neuroimage 6:218-229. CrossRef Medline

Goldstein AN, Walker MP (2014) The role of sleep in emotional brain function. Annu Rev Clin Psychol 10:679-708. CrossRef Medline

Goldstein AN, Greer SM, Saletin JM, Harvey AG, Nitschke JB, Walker MP (2013) Tired and apprehensive: anxiety amplifies the impact of sleep loss on aversive brain anticipation. J Neurosci 33:10607-10615. CrossRef Medline

Gujar N, McDonald SA, Nishida M, Walker MP (2011a) A role for REM sleep in recalibrating the sensitivity of the human brain to specific emotions. Cereb Cortex 21:115-123. CrossRef Medline

Gujar N, Yoo SS, Hu P, Walker MP (2011b) Sleep deprivation amplifies reactivity of brain reward networks, biasing the appraisal of positive emotional experiences. J Neurosci 31:4466-4474. CrossRef Medline

Hedner J, Pillar G, Pittman SD, Zou D, Grote L, White DP (2004) A novel adaptive wrist actigraphy algorithm for sleep-wake assessment in sleep apnea patients. Sleep 27:1560-1566. Medline

Hedner J, White DP, Malhotra A, Herscovici S, Pittman SD, Zou D, Grote L, Pillar G (2011) Sleep staging based on autonomic signals: a multi-center validation study. J Clin Sleep Med 7:301-306. CrossRef Medline

Herscovici S, Pe'er A, Papyan S, Lavie P (2007) Detecting REM sleep from the finger: an automatic REM sleep algorithm based on peripheral arterial tone (PAT) and actigraphy. Physiol Meas 28:129-140. CrossRef Medline

Hoddes E, Zarcone V, Smythe H, Phillips R, Dement WC (1973) Quantification of sleepiness: a new approach. Psychophysiology 10:431-436. CrossRef Medline

Iordan AD, Dolcos S, Dolcos F (2013) Neural signatures of the response to emotional distraction: a review of evidence from brain imaging investigations. Front Hum Neurosci 7:200. CrossRef Medline

Keil A, Gruber T, Müller MM, Moratti S, Stolarova M, Bradley MM, Lang PJ (2003) Early modulation of visual perception by emotional arousal: evidence from steady-state visual evoked brain potentials. Cogn Affect Behav Neurosci 3:195-206. CrossRef Medline

Keil A, Stolarova M, Moratti S, Ray WJ (2007) Adaptation in human visual cortex as a mechanism for rapid discrimination of aversive stimuli. Neuroimage 36:472-479. CrossRef Medline

Killgore WD, Balkin TJ, Wesensten NJ (2006) Impaired decision making following $49 \mathrm{~h}$ of sleep deprivation. J Sleep Res 15:7-13. CrossRef Medline

Kim MJ, Loucks RA, Palmer AL, Brown AC, Solomon KM, Marchante AN, Whalen PJ (2011) The structural and functional connectivity of the amygdala: from normal emotion to pathological anxiety. Behav Brain Res 223:403-410. CrossRef Medline

Lachaux JP, Rodriguez E, Martinerie J, Varela FJ (1999) Measuring phase synchrony in brain signals. Hum Brain Mapp 8:194-208. CrossRef Medline

Lang PJ, Bradley MM, Cuthbert BN (1999) International affective picture system (IAPS): technical manual and affective ratings. Gainesville, FL: University of Florida, Center for Research in Psychophysiology.

Leppänen JM, Milders M, Bell JS, Terriere E, Hietanen JK (2004) Depression biases the recognition of emotionally neutral faces. Psychiatry Res 128:123-133. CrossRef Medline

Lim J, Dinges DF (2008) Sleep deprivation and vigilant attention. Ann NY Acad Sci 1129:305-322. CrossRef Medline

Mauss IB, Troy AS, LeBourgeois MK (2013) Poorer sleep quality is associated with lower emotion-regulation ability in a laboratory paradigm. Cogn Emot 27:567-576. CrossRef Medline

Miller EK, Cohen JD (2001) An integrative theory of prefrontal cortex function. Annu Rev Neurosci 24:167-202. CrossRef Medline

Minkel JD, Banks S, Htaik O, Moreta MC, Jones CW, McGlinchey EL, Simpson NS, Dinges DF (2012) Sleep deprivation and stressors: evidence for elevated negative affect in response to mild stressors when sleep deprived. Emotion 12:1015-1020. CrossRef Medline

Mueller ST, Piper BJ (2014) The Psychology Experiment Building Language (PEBL) and PEBL test battery. J Neurosci Methods 222:250-259. CrossRef Medline

Müller MM, Andersen SK, Keil A (2008) Time course of competition for visual processing resources between emotional pictures and foreground task. Cereb Cortex 18:1892-1899. CrossRef Medline

Muzur A, Pace-Schott EF, Hobson JA (2002) The prefrontal cortex in sleep. Trends Cogn Sci 6:475-481. CrossRef Medline

Nilsson JP, Söderström M, Karlsson AU, Lekander M, Åkerstedt T, Lindroth NE, Axelsson J (2005) Less effective executive functioning after one night's sleep deprivation. J Sleep Res 14:1-6. CrossRef Medline

Nishida M, Pearsall J, Buckner RL, Walker MP (2009) REM sleep, prefrontal theta, and the consolidation of human emotional memory. Cereb Cortex 19:1158-1166. CrossRef Medline

Ochsner KN, Gross JJ (2005) The cognitive control of emotion. Trends Cogn Sci 9:242-249. CrossRef Medline 
Ochsner KN, Silvers JA, Buhle JT (2012) Functional imaging studies of emotion regulation: a synthetic review and evolving model of the cognitive control of emotion. Ann NY Acad Sci 1251:E1-E24. CrossRef Medline

Okon-Singer H, Lichtenstein-Vidne L, Cohen N (2013) Dynamic modulation of emotional processing. Biol Psychol 92:480-491. CrossRef Medline

Okon-Singer H, Mehnert J, Hoyer J, Hellrung L, Schaare HL, Dukart J, Villringer A (2014) Neural control of vascular reactions: impact of emotion and attention. J Neurosci 34:4251-4259. CrossRef Medline

O'Reilly JX, Woolrich MW, Behrens TE, Smith SM, Johansen-Berg H (2012) Tools of the trade: psychophysiological interactions and functional connectivity. Soc Cogn Affect Neurosci 7:604-609. CrossRef Medline

Owen AM, McMillan KM, Laird AR, Bullmore E (2005) N-back working memory paradigm: a meta-analysis of normative functional neuroimaging studies. Hum Brain Mapp 25:46-59. CrossRef Medline

Payne JD, Chambers AM, Kensinger EA (2012) Sleep promotes lasting changes in selective memory for emotional scenes. Front Integr Neurosci 6:108. CrossRef Medline

Penzel T, Kesper K, Pinnow I, Becker HF, Vogelmeier C (2004) Peripheral arterial tonometry, oximetry and actigraphy for ambulatory recording of sleep apnea. Physiol Meas 25:1025-1036. CrossRef Medline

Perlstein WM, Elbert T, Stenger VA (2002) Dissociation in human prefrontal cortex of affective influences on working memory-related activity. Proc Natl Acad Sci U S A 99:1736-1741. CrossRef Medline

Pessoa L (2008) On the relationship between emotion and cognition. Nat Rev Neurosci 9:148-158. CrossRef Medline

Pessoa L, McKenna M, Gutierrez E, Ungerleider LG (2002) Neural processing of emotional faces requires attention. Proc Natl Acad Sci U S A 99: 11458-11463. CrossRef Medline

Pilcher JJ, Huffcutt AI (1996) Effects of sleep deprivation on performance: a meta-analysis. Sleep 19:318-326. Medline

Pillar G, Bar A, Betito M, Schnall RP, Dvir I, Sheffy J, Lavie P (2003) An automatic ambulatory device for detection of AASM defined arousals from sleep: the WP100. Sleep Med 4:207-212. CrossRef Medline

Pourtois G, Schettino A, Vuilleumier P (2013) Brain mechanisms for emotional influences on perception and attention: what is magic and what is not. Biol Psychol 92:492-512. CrossRef Medline

Singer N, Eapen M, Grillon C, Ungerleider LG, Hendler T (2012) Through the eyes of anxiety: dissecting threat bias via emotional-binocular rivalry. Emotion 12:960-969. CrossRef Medline

Somerville LH, Kim H, Johnstone T, Alexander AL, Whalen PJ (2004) Human amygdala responses during presentation of happy and neutral faces: correlations with state anxiety. Biol Psychiatry 55:897-903. CrossRef Medline

Sotres-Bayon F, Bush DE, LeDoux JE (2004) Emotional perseveration: an update on prefrontal-amygdala interactions in fear extinction. Learn Mem 11:525-535. CrossRef Medline

Tempesta D, Couyoumdjian A, Curcio G, Moroni F, Marzano C, De Gennaro L, Ferrara M (2010) Lack of sleep affects the evaluation of emotional stimuli. Brain Res Bull 82:104-108. CrossRef Medline

Thayer JF, Lane RD (2000) A model of neurovisceral integration in emotion regulation and dysregulation. J Affect Disord 61:201-216. CrossRef Medline

Turner TH, Drummond SP, Salamat JS, Brown GG (2007) Effects of $42 \mathrm{hr}$ of total sleep deprivation on component processes of verbal working memory. Neuropsychology 21:787-795. CrossRef Medline

Tzourio-Mazoyer N, Landeau B, Papathanassiou D, Crivello F, Etard O, Delcroix N, Mazoyer B, Joliot M (2002) Automated anatomical labeling of activations in SPM using a macroscopic anatomical parcellation of the MNI MRI single-subject brain. Neuroimage 15:273-289. CrossRef Medline

van der Helm E, Yao J, Dutt S, Rao V, Saletin JM, Walker MP (2011) REM sleep depotentiates amygdala activity to previous emotional experiences. Curr Biol 21:2029-2032. CrossRef Medline

Van Dillen LF, Heslenfeld DJ, Koole SL (2009) Tuning down the emotional brain: an fMRI study of the effects of cognitive load on the processing of affective images. Neuroimage 45:1212-1219. CrossRef Medline

Walker MP, van der Helm E (2009) Overnight therapy? The role of sleep in emotional brain processing. Psychol Bull 135:731-748. CrossRef Medline

Watson D, Clark LA, Tellegen A (1988) Development and validation of brief measures of positive and negative affect: the PANAS scales. J Pers Soc Psychol 54:1063-1070. CrossRef Medline

Yamasaki H, LaBar KS, McCarthy G (2002) Dissociable prefrontal brain systems for attention and emotion. Proc Natl Acad Sci U S A 99:1144711451. CrossRef Medline

Yoo SS, Gujar N, Hu P, Jolesz FA, Walker MP (2007) The human emotional brain without sleep-a prefrontal amygdala disconnect. Curr Biol 17: R877-R878. CrossRef Medline

Zhong X, Hilton HJ, Gates GJ, Jelic S, Stern Y, Bartels MN, Demeersman RE, Basner RC (2005) Increased sympathetic and decreased parasympathetic cardiovascular modulation in normal humans with acute sleep deprivation. J Appl Physiol 98:2024-2032. CrossRef Medline

Zohar D, Tzischinsky O, Epstein R, Lavie P (2005) The effects of sleep loss on medical residents' emotional reactions to work events: a cognitiveenergy model. Sleep [Erratum (2005) 28:385] 28:47-54. Medline 